\title{
How and Why Interviews Work: Ethnographic Interviews and Meso-level Public Culture ${ }^{1}$
}

\author{
By Rachel Rinaldo and Jeffrey Guhin
}

\begin{abstract}
Recent debates about qualitative methods have discussed the relative limitations and contributions of interviews in comparison to surveys and participant observation. These discussions have rarely considered how ethnographers themselves use interviews as part of their work. We suggest that Lizardo's (2017) discussion of three modes of culture (declarative, nondeclarative, and public) help us to understand the separate contributions of observation and interviews, with ethnographic interviews an especially helpful means of accessing different cultural modes. We also argue that Lizardo's conception of public culture should be divided into meso and macro levels, and that this division helps to show the differing contributions of interviews within and without an ethnographic context. Developing our argument with data from the second author's ethnographic research and analysis of other scholars' ethnographies, we show how research that uses ethnographic interviews can help sociologists better understand how these four cultural modes interact.
\end{abstract}

Recent critiques of the social scientific use of interviews in comparison to surveys (Vaisey 2009) and ethnography (Duneier 2007, Jerolmack and Khan 2014) can miss the important role interviews play in understanding not only how actors think about and process events through particular cultural structures (Kitsuse 1962, Cicourel 1982, Lamont 1992, Maynard and Schaeffer 2000, Swidler 2001; Viterna and Maynard 2002, Pugh 2013, Lamont and Swidler 2014) but also how interviews can function within ethnographic work to reveal culture interactions more complex than standard binaries of saying versus doing.

In this paper, we use Omar Lizardo's recent work on different modes of culture (2017) to describe how ethnographic interviews help scholars to distinguish between what Lizardo calls declarative, nondeclarative, and public modes of culture. Although Lizardo does not define "modes of culture," we understand this concept to encapsulate different ways of experiencing, encoding, and expressing cultural knowledge. We also argue that Lizardo’s work, like much sociological analysis, presumes a dichotomy between broad macro-level cultural structures and individual-level cognition; we resolve this lacuna by dividing Lizardo's concept of public culture into two levels: the meso and the macro. This division between meso and macro allows sociologists to better articulate the 
difference between interviews with and without ethnographic context. Interviews outside of an ethnography are by no means simply "cheap" talk: they are able to examine the interactions of the macro public with the private declarative. However, it is only interviews within an ethnographic context that give scholars access to each cultural mode.

While Lizardo's argument is sensitive to the complex ways in which an individual can learn both knowledge that and knowledge how (Ryle 1945-1946), it is less sensitive to the space between what he calls "public culture" and individual culture. Ethnographic interviews-that is, interviews conducted within a specific social location—help to fill this gap. As Lizardo himself hints, his concept of "public culture" is exceedingly broad (2017: 96), and it cannot distinguish between broad "public" culture and what we refer to here as "meso-level" public culture, that is, culture that is contained within a specific social location. We distinguish this from macro-level public culture, which is often what is revealed in sociological work based entirely on interviews.

Of course, interviews are often a part of ethnographic research. Indeed, there are very few ethnographies that do not entail at least some conversations between the ethnographer and her research subjects regarding her research questions, as we will discuss further below. Those conversations might or might not be recorded, scheduled, and systematic, yet most ethnographers feel a need to talk to people rather than simply to watch them. Lizardo's article helps to articulate why this triangulation matters: observation and conversation help sociologists to understand the interactions between different cultural modes. Yet we would suggest that Lizardo's distinction do not go far enough to show the specific mode of the meso level in public culture, and we would further suggest that an important role of ethnographic interviews is to reveal how this meso-level public culture interacts with the other modes Lizardo describes.

Interviews do not necessarily require this ethnographic context to produce reliable data. As Pugh (2013) describes, only the most naïve interviewer believes she is simply gaining access to 
information: the interview instead ought to be regarded as a social experience with moments of interaction between ideas, emotions, and cultural frames (Wuthnow 2011). While various scholars have recently defended the interview methodology along these lines (Cerulo 2014, Pugh 2013), they have generally continued to describe interviews as analytically and methodologically distinct from ethnography. In contrast, this article describes how and why interviews within the context of an ethnography help scholars to reveal the meso level of public culture as well as its interactions with other cultural modes.

For Lizardo, the declarative and nondeclarative modes of culture are both cognitive cultural domains contained within the individual, although they are contained in different mental locations and built upon different kinds of learning. Declarative culture is rooted in language or other symbolic forms and can be learned quickly but tends to involve judgement and reason to access; Nondeclarative culture is rooted in bodily practice and requires more time to internalize. These cultural modes can be redundant, and it is just as possible that someone might be able to say but not do as they might be able to do but not say.

It is also worth pointing out here that while Lizardo is primarily focused on the personal quality of declarative and nondeclarative culture, the idea of a wholly "personal" culture is something of an oxymoron, in a sense similar to Wittgenstein's denial of the possibility of a private language (2009). Personal declarative culture and nondeclarative culture are those elements of the culture contained within a person, whether their memories or future plans, their speech or thoughts, their bodily activities or bodies themselves. Yet actual culture — whether practiced declaratively or nondeclaratively — is necessarily at once public and personal; otherwise it is hard to recognize it as culture, for, despite its multitudinous definitions, "culture" is nearly always understood as something with a social basis (Durkheim 1995, Mears 2014, Mohr and Ghaziani 2014). 
What is important about Lizardo's work is how he shows that declarative and nondeclarative cultural modes are both experienced (by research subjects) and observed and interpreted (by sociologists) differently; As Lizardo and others show, certain methodologies are better at accessing certain modes of culture: interviews, with their attention to speech acts, can better observe the declarative, while ethnography with its attention to observation and experience — and, to some extent, surveys (Vaisey 2009)—can better observe the nondeclarative. Of course, careful interviewers can figure out the nondeclarative within an interview (Pugh 2013, Pugh 2014), just as careful ethnographers can find people's declarations about what a certain practice means. Yet what about public culture, which, for Lizardo, consists of "public symbols, discourses, and institutions" (2017: 93)? Lizardo's understanding of public culture is quite capacious. managing to include Swidler's toolkit (1986, 2001), Alexander and Smith's strong program (Alexander 2006, Alexander and Smith 2010), Bourdieu's “strong practice theory" (Bourdieu 1990, Lizardo and Strand 2010) and the "group styles" of Eliasoph and Lichterman (2003). These various thinkers are given as examples of the distinct ways that public culture can intersect with either declarative culture or nondeclarative culture, either tightly (with declarative, Alexander; with nondeclarative, Bourdieu) or loosely (with declarative, Swidler; with nondeclarative, the "semiotic practice theory" of various authors, including Biernacki (1995), Sewell (1992), and Eliasoph and Lichterman (2003).

Yet it is worth acknowledging, as Lizardo himself does, that this capaciousness, however advantageous for the sake of a more parsimonious argument, might have analytical limitations. Lizardo (2017: 96) suggests that public culture might be cut into its declarative and nondeclarative elements, but it could just as easily (and, for our purposes, more advantageously) be differentiated into a macro level and a meso level. We suggest this division because, as with Lizardo's original argument, the distinction provides a helpful means of understanding how sociological projectsespecially those with interviews_-reveal different kinds of culture in different kinds of work. We will 
show the empirical payoff through an analysis Lizardo himself references_Eliasoph and Lichterrman's "Culture in Action" (2003)_ as well as through an analysis of Guhin (the second author)'s research project.

Building on Lizardo's article, we suggest that ethnographic interviews are useful for two reasons. First they help scholars gain access to the intersection and interaction of all three modes Lizardo suggests: declarative, nondeclarative, and public, helping to push against an over simplistic binary of saying versus doing (Decoteau 2016). Second, they help us understand how public culture itself is divided into a macro and a meso level, with ethnographic interviews uniquely situated to give access to how that meso-level public culture interacts with the other cultural modes.

\section{The Spectrum Between Surveys and Observations}

This article contributes to an ongoing methodological discussion in sociology that has centered on what is gained through surveys, interviews, and ethnography. One of the most prominent contributors to these discussions, Vaisey (2009) has built on Haidt's dual process model (2001) (an argument similar to Kahneman's "thinking fast and slow" (2011)) to argue that the theory of dual modes of cognition can help sociologists understand how ideas are connected to action. According to Vaisey (2009), answers on forced question surveys are better predictors of future action than interviews, because deeply internalized ideas are more closely connected to motivating (as opposed to justifying) action.

Lizardo's response to the article is in part a rejection of this dichotomy, arguing that speech is not necessarily fast and practices are not necessarily slow; in a similar way, as we will show below, Eliasoph and Lichterman show how certain speech norms are themselves babituated practices and not simply freely chosen "declarations." Yet much of the response to Vaisey's article has been a defense of the methodological value of interviews. Pugh (2013) argues that interviews demonstrate the 
intersections between ideas, emotions, and cultural frames, thereby providing different kinds of data than surveys: the paradoxes are the point, she argues, as opposed to Vaisey's commitment to predictive power (Pugh 2014, Vaisey 2014). In a different vein, Jerolmack and Khan (2014) claim that both interviews and surveys are problematic - e.g. that "talk is cheap" - because they equate attitudes to behavior. They propose that ethnography is superior to interviews because actions generally occur within specific situations. By observing events and interactions in situ, an ethnographer can provide more accurate information about how or whether ideas translate into action. Yet ideas — and the cultural structures that contain them-are often important as objects in themselves (Lamont and Swidler 2014), something that can be lost by privileging in situ data gathering above interviewing (Wuthnow 2011).

In some ways, these not entirely new debates are what Abbot describes as the repeated iterations of intellectual cycles (2001): a generation discovers a problem, litigates it, and then moves onto other problems, leaving the discussion to a later generation to once more discover. The contours of this debate- both its questioning of a focus on habits versus a focus on the situation and its explicit questioning of the role of interviews — goes back at least as far as C. Wright Mills's classic article on "situated actions and vocabularies of motive" (1940) while its philosophical questions about the nature of human action go to much older sociological generations (Blumer 1986, Mead 1967).

Neither is it new to claim that knowledge can be divided into "knowledge that" (discursive/declarative) and "knowledge how" (non-discursive/nondeclarative) (Ryle 2009). However, it is new to suggest, as Lizardo does, that such different forms of knowledge map onto different modes of culture and that such distinctions can help us make sense of contemporary debates about culture, and as such, can also help us to clarify the relationship of interviews to ethnography. This article should be understood in just such an imminent way: not making a 
universal claim to settle ancient debates once and for all but rather using contemporary discussions to provide better clarity for all involved.

That clarity comes in the form of two questions: (1) What are interviews good for and (2) Why and how are interviews helpful within an immersive or ethnographic context? The first question is already much discussed in books, articles, lectures, and seminars on qualitative methodology (Riesman and Benney 1956, Warren 2012, Weiss 1995) and in many ways the question is unanswerable because interviews are such a heterogeneous category. For example, do we mean survey interviews (Cicourel 1982, Maynard and Schaeffer 2000, Viterna and Maynard 2002) that are painstakingly ordered to maintain consistency? Or do we mean more free-flowing open-ended or focused interviews (Charmaz 2006, Merton, Fiske and Kendall 1990)? Or something in between? Yet in most cases, interviews intend to discover something about an individual's experience that is necessarily declarative: interviews happen via words. That does not mean interviews cannot also elicit non-verbal responses that are worth studying and which might relate to elements of nondeclarative culture (Pugh 2014) and neither does it mean that speech always comes from habituation, norms, and socialized routines (Eliasoph and Lichterman 2003). Nonetheless verbal responses tend to be the focus of interview analysis.

While we find many of the above discussions useful for justifying interviews as methods, we argue that these discussions do not go far enough to show why and how interviews are important for qualitative research, what role they play in ethnography, and how they relate to the interactions of different modes of culture. We suggest that ethnography and interviews should be thought of as being on a spectrum rather than as dichotomous categories. What differentiates the stages in this spectrum is both immersion in a place (virtual or physical) and access to respondents' declarative culture as revealed in conversations with the ethnographer. To be clear, these stages are important 
not because of the interviews themselves but because of the way the interviews interact with other methods,

thereby giving access to particular interactions of cultural modes.

Table 1: A Spectrum from Surveys to Observation

\begin{tabular}{|c|c|c|c|c|}
\hline Stage & Name & $\begin{array}{l}\text { Selection of } \\
\text { Interviewees }\end{array}$ & $\begin{array}{l}\text { Role of Interviews in } \\
\text { Overall Project }\end{array}$ & Examples \\
\hline Stage One & Randomized Interview & $\begin{array}{l}\text { Intentionally } \\
\text { random across a } \\
\text { population }\end{array}$ & Total & $\begin{array}{l}\text { Large survey } \\
\text { instruments } \\
\text { with open- } \\
\text { ended } \\
\text { questions } \\
\end{array}$ \\
\hline Stage Two & $\begin{array}{l}\text { Semi-Randomized } \\
\text { Interview }\end{array}$ & $\begin{array}{l}\text { Intentionally } \\
\text { random or by } \\
\text { snowball sample, } \\
\text { emphasizing key } \\
\text { variables, e.g. race, } \\
\text { class, or religion }\end{array}$ & Total & $\begin{array}{l}\text { Lamont (2009) } \\
\text { Luker (2007) }\end{array}$ \\
\hline Stage Three & $\begin{array}{l}\text { Primary Ethnographic } \\
\text { Interview }\end{array}$ & $\begin{array}{l}\text { Respondents are } \\
\text { chosen from a } \\
\text { specific field site (or } \\
\text { a small number of } \\
\text { similar field sites) }\end{array}$ & $\begin{array}{l}\text { Formal interviews } \\
\text { are the driving } \\
\text { method, but they are } \\
\text { supported by } \\
\text { ethnographic } \\
\text { context. }\end{array}$ & $\begin{array}{l}\text { Young (2006) } \\
\text { Edin and } \\
\text { Kefalas (2011) }\end{array}$ \\
\hline Stage Four & $\begin{array}{l}\text { Contextual } \\
\text { Ethnographic Interview }\end{array}$ & $\begin{array}{l}\text { Ethnographers } \\
\text { select }\end{array}$ & $\begin{array}{l}\text { Formal interviews } \\
\text { support the } \\
\text { ethnography, or they } \\
\text { support each other. }\end{array}$ & $\begin{array}{l}\text { Most } \\
\text { contemporary } \\
\text { ethnographies } \\
\text { are in this } \\
\text { category. } \\
\text { Eliasoph } \\
\text { (1998) } \\
\text { Lichterman } \\
(1996) \\
\end{array}$ \\
\hline Stage Five & $\begin{array}{l}\text { Participant Observation } \\
\text { Conversations }\end{array}$ & $\begin{array}{l}\text { Respondents are } \\
\text { part of a specific } \\
\text { ethnographic field } \\
\text { site and are only } \\
\text { engaged as part of } \\
\text { an ethnographer's } \\
\text { participation } \\
\text { observation in that } \\
\text { field site }\end{array}$ & $\begin{array}{l}\text { There are no separate } \\
\text { formal interviews, } \\
\text { but the participant } \\
\text { observer does have } \\
\text { conversations that } \\
\text { elicit declarative } \\
\text { and/or } \\
\text { nondeclarative } \\
\text { culture. }\end{array}$ & $\begin{array}{l}\text { Goffman } \\
(1956) \\
\text { Goodman } \\
\text { (2008) } \\
\text { Katz (1996) }\end{array}$ \\
\hline Stage Six & Observation & $\begin{array}{l}\text { Respondents are not } \\
\text { interviewed }\end{array}$ & $\begin{array}{l}\text { There are no } \\
\text { interviews, nor even } \\
\text { interaction between } \\
\text { the ethnographer and } \\
\text { those in the field site. }\end{array}$ & $\begin{array}{l}\text { Classroom } \\
\text { observations in } \\
\text { which the } \\
\text { ethnographer } \\
\text { can have no } \\
\text { interaction } \\
\text { with teacher or } \\
\text { students; } \\
\text { Gibson (2008) }\end{array}$ \\
\hline
\end{tabular}


As Table 1 demonstrates, we suggest a spectrum that includes six stages. First there are Randomized Interviews, such as those that might be conducted for a large survey study with openended questions. The second stage is Semi-Randomized Interviews, projects, like those of Lamont (1992, 2009), or Luker (2007) that build upon interviews with respondents chosen to represent a particular variable, such as gender, race, or employment status. While geography might be one of these variables, it is not important that the respondents come from identical places, even if they might come from similar social locations, e.g. there might be a desire to interview various people who are African American and Muslim (Husain 2017). Place or location is not necessarily relevant for these interviews, except in as much as respondents share a capacity to connect to a broad macrolevel culture, such as all being American, French, or Evangelical Protestant. These interviews might or might not focus on a certain context: they might pay attention to the condition of the respondent's home, or work, or life, but they do not reveal a meso-level culture shared with other respondents.

Stages three and four contain what we would refer to as ethnographic interviews and will be discussed further below. These interviews might or might not be tape-recorded or fully planned, but they are deliberate and relatively formal interviews. Stage five (also discussed below), which we call Participant Observation, includes only informal or casual conversations rather than interviews. These sorts of conversations happen in any ethnography, so they are part of stages four and three as well. The difference with stage five is that these conversations are ethnographers' only access to declarative culture, as opposed to in stages three and four, where declarative culture is also available in formal interviews.

Stage six, Observation, is a form of ethnography that does not contain any speech between the speaker and the respondents, such as classroom observations in which the speaker can only 
observe the class and cannot interview anyone involved. One of the few examples of such research is Gibson's (2008) study of line formation in train studies, which is based on field observations and photographs.

For stages three through five, the ethnographer is able to triangulate between respondents' talk and their own observations to gain a sense of a meso-level culture as well as how Lizardo's other cultural modes interact with each other.

Stage three, which we refer to as Primary Ethnographic Interviews, is primarily about the interviews themselves, but the interviews are selected in such a way that they provide an awareness of the meso-level culture that surrounds them. For example, Young (2006) chose respondents for his work from two housing projects, both within the same neighborhood, about which Young had extensive ethnographic experience. Similarly, in Promises I Can Keep (2011), Edin and Kefalas are primarily interested in interviews, but they root these interviews in an extensive ethnographic knowledge of the places where these interviews were conducted. These interviews are frequently conducted at a physical field site, which could be as small as a particular group of people or as large as a town or city. But they could also include interviews conducted as part of a multi-sited project (Marcus 1995), or the field site could be virtual, as in the case of Burke's (2016) recent analysis of sexuality in Christian online forums and interviews with bloggers and participants in those forums. What differentiates this from Stage two is the effort to understand participants within a specific meso-level context and the researcher also being immersed in this context.

Stage four, which we refer to as the Contextual Ethnographic Interview, contains deliberate, intentional interviews as part of a broader ethnographic project, in which it is the ethnography, rather than the interviews, which is forefronted in the methodological goals. Similar to the above, the ethnographic field site could be physical or virtual, or constructed as a set of relations or processes that are geographically or otherwise bounded (Desmond 2014). In this Stage, the 
researcher is not only immersed in the context but using both interviews and her own observations or experiences as data. The interviews may or may not be tape-recorded or structured with a particular set of questions, though often they are. However, the interview is not simply the result of conversations that may have happened anyway as a result of participant observation, which is how we characterize interviews in stage five.

Stage five, which we refer to as Participant Observation, has no formal interviews (that is, time in private between the respondent and the sociologist in which certain pre-established questions are asked), but the ethnographer regularly interacts with respondents and has casual conversations that often reveal the kinds of declarative culture discovered in interviews. These conversations (such as asking "hey what's that about") of a respondent during a field site provoke in situ interactions, often involving more than one respondent. These lead to different sorts of interactions than we might find in a more formal interview (Goodman 2008, Katz 1996). Many older ethnographies such as Goffman (1956) as well as some anthropological ethnographies exemplify stage five. However, it is worth noting that very few contemporary sociological ethnographies fit into stage five: most contain at least a few interviews that are separate from the "action" and if they do not, it is often because of practical constraints rather than for methodological reasons.

Distinguishing between these stages helps to show why the difference between meso-level and macro-level public culture matters. Interviews in stages one and two require knowledge of broader cultural structures (what Lizardo calls "public culture") to make sense of them. This public culture is usually quite broad (often portrayed as being at the national level) which is a function both of the breadth of respondents and of scholars' desire for their work to be generalizable. Even interviews with seemingly non-cultural questions (e.g. questions about voting or work habits) must be interpreted through social scientists' awareness that certain questions activate norms within society regarding, in these cases, voting and work ethic. It might well be the case that these 
respondents' declarations are contrary to their nondeclarative practices, or at least, that the connection between the two is loosely rather than tightly coupled. Yet that is not necessarily a problem if the point of the work is to reveal how ironies and tensions within macro-level public culture are made manifest in people's talk (Bellah et al. 2007, Lamont 2009, Luker 2007, Swidler 2001).

Note that both of Lizardo's key examples of public culture connecting to declarative culture occur at this macro level. He cites a strong coupling of declarative and public culture in Alexander and Smith's "Strong Program" analysis of the cultural codes revealed in newspaper articles and legislative debates. Lizardo also cites Swidler's use of interviews outside of an ethnographic context (what we would call Stage Two) in Talk of Love (2001) and "Culture in Action" (1986), though we could also add Habits of the Heart (2007), as all three link declarative commitments to broad macrolevel public culture (Eliasoph and Lichterman 2003: 743). In contrast to those who argue that interviewers ignore the situation, we argue that good interviewers are entirely capable of grasping the situated nature of these interviewees, and, indeed, their situatedness within public discourse provides much of the analytic payoff, revealed in intriguing tensions, counterintuitive claims, or unexpected similarities across difference (Cerulo 2014, Lamont and Swidler 2014, Pugh 2013). Yet that situatedness is at the intersection of the personal declarative with the public macro, something which is certainly interesting and worthwhile, but not necessarily complete. To get at the personal nondeclarative and the public meso, we will need other methods.

For example, Lamont's The Dignity of Working Men (2009) examines how narratives about morality are tied to ideas about race, class, and nation for French and American men. Lamont is interested in narratives and what they tell us about national culture, so it makes sense to rely entirely on interview data. Similarly, Gerson's Unfinished Revolution: Coming of Age in a New Era of Gender, Work, and Family (2009) uses interview data to argue that social and economic forces make it very difficult 
for young people to live out egalitarian gender values. As for Lamont, it is the discussions and declarations (and the contradictions within them) that are of interest to Gerson. Ethnographers sometimes criticize these sorts of arguments, claiming they do not spend enough time observing respondents' actual practices, rendering the talk at least potentially "cheap." Yet these criticisms can miss the interactions between cultural modes they seek to identify: as Lizardo helpfully articulates, these works seek the interaction between declarative and public culture. The nondeclarative is another matter.

Yet there is a further specification to be made here: these broad studies examine public culture at the macro level. In contrast, ethnographic interviews (stages three and four in our spectrum) have a much better ability to examine public culture at the meso level and, perhaps more importantly, to show the interaction of the macro and meso levels of public culture, as we will show in our analysis of Eliasoph and Lichterman's argument below.

\section{Meso-level Culture}

As with Lizardo's broader concept of "public culture," the terms "meso-level culture" and "macro-level culture" are expansive enough to include both the declarative and nondeclarative domains. The key distinction is not between practices and speech here, but between various levels of social interaction. This change in focus can help sociologists move past a possible methodological individualism Pugh identifies in the dual process model (DPM) (2013:47) and which Vaisey later defends against (2014: 152-153). Whether or not the DPM is individualist, both the DPM and Lizardo's model of cultural modes presumes a dichotomy between the broad public and the personal, or, at least, neither theory specifies the difference between meso-level and macro-level social effects. 
While we have emphasized how ethnographers gain meso-level context through interviews, they can also do so through archival work, especially in the study of a particular organization with extensive records. For example, in Vaughan's The Challenger Launch Decision (1997), she triangulates between NASA documents, government archives, and interviews to help her understand how what had initially appeared to be rule violations were actually part of an organizational culture that encouraged what were defined as acceptable risks (Vaughan 2004). She argues that both the archival documents and interview transcripts were crucial for a more complete understanding of the particular culture(s) of NASA. While Vaughan classifies such work as "historical ethnography" (2004), it is actually not important for our argument whether her work is or is not ethnographic: the important piece is that the interviews are embedded within a broader meso-level culture and that various data points help reveal that meso-level culture in a way that randomized interview based studies cannot accomplish. In that sense, Vaughan's work can be classified as part of stage four, using interviews as a means of triangulating a specific meso-level public culture.

As we understand it, meso-level public culture consists of the organizational rules, social groups, and institutional norms that have an important influence on beliefs and practices of both groups and individuals within a certain social setting. Importantly, this is a public culture, meaning that it is shared and emergent from aggregated individuals. Precisely because meso is separate from other levels of culture, it is therefore able to interact with both individual level culture one level below (micro e.g. Lizardo's declarative and nondeclarative) and public culture one level above (macro). Meso-level cultures might include schools, neighborhoods, workplaces or firms, religious or civic organizations, social movements, or political associations. Sometimes, the social scientist will not even be aware of the meso-level culture until she begins talking to people.

A social scientist can get some access to this meso-level culture simply by watching what people do and she might be able to hypothesize about the meso level through careful study of 
randomly gathered surveys or interview transcripts, such as when survey researchers hypothesize about certain meso-level mechanisms that might explain differing outcomes in the life course. Yet, as we will show in our empirical sections, ethnographic interviews (stages three and four in table one) provide a way of describing how such meso-level culture works and how it is understood and navigated by respondents, allowing for certain kinds of questions that other kinds of interviews or simple observation do not allow.

For example, Kligman and Verdery (2011) use archival contexts and interviews between and across villages to understand Romania's agricultural collectivization, thereby demonstrating "the crucial difference between simply carrying out interviews and doing so in the context of extended ethnographic research" (2011:31). They write:

...oral sources can expose the pitfalls of literal readings of official written sources, especially penal files. In the Securitate files, [Kligman] came across a list of punishments meted out to alleged members of the "Popşa terrorist gang," one of which was for a person listed as "missing" and tried in absentia. After interviewing this man's sister, Kligman went on to find official confirmation that the security forces had "mortally wounded" him. At the time of his sentencing, then, he was not actually missing but dead and buried. While a seeming detail, the difference between "missing" and "dead" is significant for the historical record: the regime's cynicism and brutality were effaced under the ubiquitous category of "missing." Had it not been for the interviews, Kligman would have read "missing" as just that, a name attached to a statistical category. In cases like this, the dialogic interplay between oral and archival knowledge transforms our understanding of what is represented in the official register in relation to what actually happened (2011: 38).

Kligman's and Verdery's work did not end at the triangulation of archives and interviews; they were able to hold various data against each other, including interviews with respondents in multiple 
villages and also respondents' body language and emotional affects during those interviews. Linking all of these with the co-investigators' local knowledge of all four modes of culture helped to make their argument at once more nuanced and more accurate.

Yet accuracy is a complicated term, and what appears a matter of accuracy may actually be a matter of differing vocabularies (Mills 1940) or distinct modes of culture (Lizardo 2017). Jerolmack and Khan (2014) are surely right that people's attitudes and behaviors often vary widely and that some people misrepresent their practices in their talk. Yet this difference between attitude and behavior, like the difference between habit and situation, is actually as much a theoretical problem as a methodological one (Tavory 2018): careful sociologists can use particular contexts to find the situations in which there is a robust connection between particular attitudes and behaviors or in which particular commitments maintain themselves across a variety of situations, even as other commitments can vary depending on the degree to which they are "summoned," as Tavory describes in his study of Orthodox Jews (Tavory 2016). It is a problem of examining how different cultural modes are evoked rather than a question of choosing which is more correct.

While Lizardo's three modes of culture help show how this theoretical openness can resolve certain methodological debates about the study of culture, his distinctions do not quite resolve questions about what interviews reveal. When people reveal public culture in their discourse (as Lizardo describes), they are not always revealing public culture at the same level. It is this ability to distinguish between the macro and meso levels of public culture that makes ethnographic interviews so important, in addition to their ability to triangulate data, test theoretical mechanisms (Vaisey 2014), and reveal intriguing contradictions (Pugh 2013, Pugh 2014).

\section{What Does the Ethnographic Interview Do?}


Much qualitative research is entirely or mostly interview based and this work has made significant contributions to sociology. However, as discussed previously, interviews can gain access to different forms of culture if the researcher can bring to the interview itself or to the analysis of the interview, knowledge gained through immersion - including but not limited to previous interviews within the same social group, less formal interactions, observing informants in other situations, gossip from other informants, social media postings or interactions, texts produced by or that are related to the informant, local descriptive information during the interview itself, knowledge of the cultural schemas or scripts used or referred to by the informant, as well as observations and more general knowledge about the immediate neighborhood, organization, or spatial location.

Yet more information is not a good on its own. Eventually, sociological research reaches "saturation" (Small 2009) when more information becomes redundant. The additional information provided by ethnographic interviews provides two important points of analytical leverage: (1) it allows for scholars to triangulate their data, and (2) it allows for a more straightforward analysis of how the declarative culture revealed in an isolated formal interview interacts with the meso level of public culture as well as the nondeclarative culture revealed in both the interview and in ethnographic observation.

For us, the second point is key: what we call the ethnographic interview takes place not as an isolated event in a neutral environment but as part of a series of interactions and observations. The ethnographic interview cannot be understood as a thing in itself: it only becomes ethnographic to the degree that it is embedded in the kind of context that makes a meso level of public culture observable and interpretable. This meso level is only accessible after the sociologist has gained sufficient "local knowledge" (Geertz 2008) to understand meso-level cultural forms in both the declarative and nondeclarative modes, everything from shared mottos and aphorisms to the Bourdiesian doxa only visible to a critical hermeneutics. 
Of course, that meso-level research produces meso-level knowledge is not itself an important insight. What is instead important is, first, that this distinction between forms of culture helps to resolve ongoing tensions about the role of the interview, showing how different interview methodologies depend upon different levels of public culture. Second, and just as importantly, the ethnographic interview allows scholars to examine how macro-level public culture interacts with the other cultural modes, both Lizardo's declarative and nondeclarative, but also the meso level we have described here.

Our concept of the ethnographic interview draws from but is not exactly the same as previous uses of the term. Ethnographers have long conducted interviews as part of their fieldwork, but it is only in recent decades that this has been given more precise attention. Anthropologist James Spradley (1979) proposed that the interview was a crucial tool for ethnographers, and he emphasized that the interview itself is a speech event that can serve as useful data, in addition to eliciting information. Nevertheless, for Spradley, ethnographic interviews occur, either formally or informally, in the context of participant observation: "It is best to think of ethnographic interviews as a series of friendly conversations into which the researcher slowly introduces new elements to assist informants to respond as informants" (1979: 58). Spradley's conception of the ethnographic interview has been very influential for social scientists, and popular methods guides such as Emerson, Fretz, and Shaw's (2011) Writing Ethnographic Fieldnotes also acknowledge the utility of interviews during ethnography. As for Spradley, these interviews happen during traditional participant observation.

Yet this is not the only ways scholars have used the term ethnographic interview. For example, Bauman and Adair (1992) propose that the ethnographic interview is defined not by its taking place within ethnography but by particular characteristics, including being unstructured and open-ended, collecting descriptive data and focusing on everyday experience, aiming to understand 
the informants' experience from his/her point of view and treating the informants' language as data. We tend to disagree with this kind of interview as being "ethnographic" unless it reveals meso-level data that can then be checked against data gathered from the same meso-level culture. In our spectrum, we would put Bauman and Adair's method at stage two, a Semi-Randomized Interview, rather than the ethnographic interviews of stages three and four.

In this sense, our understanding of ethnography goes back to its early anthropological and sociological roots: while we hardly seeks to study an entire ethnos, we are suggesting that the role of ethnographers is generally to understand communities of people (Fine 2003) which have certain meso-level qualities not found in either the people themselves or the macro-structures that extend beyond the community. Of course, there are certain exceptions to this community-centric understanding of ethnography: one of the most important in sociology is Desmond's call for a relational (rather than group-level) ethnographic analysis (2014). Yet Desmond's work (2012, 2016) still provides a meso-level analysis of networks that is undiscoverable at either the micro or macro level. In sum, an ethnographic interview is not simply more context, it is, quite specifically, more mesolevel context. In this sense, we share Duneier's sense that the ideal ethnography "regards talk and action as dissimilar units that can only be understood in relation to another," as Duneier writes about Liebow's Tally's Corner (2003). [Tally's Corner] “is a project in comparative sociological explanation, whereby the major strategy is to compare what his subjects say against the wider context of what he has learned about them" (2007: 36).

Alford Young, one of the most prominent sociological practitioners of the ethnographic interview, notes that people's behavior is not necessarily a transparent reflection of their underlying thoughts. He argues that because ethnographic interviewing is a method that attempts to discern what people know and think about themselves and their social worlds, it is particularly well-suited for investigating "what people articulate as their own understanding of how social processes work 
and how they as individuals might negotiate the complex social terrain rather than simply looking at their actions" (2006). Young's work is focused on the interactions of his individual respondents' declarative culture with meso-level cultural structures in their neighborhood as well as macro-level cultural conceptions of African American men. Young's immersion in context along with doing interviews allows him to find (and interpret and explain) these tensions between macro-level public, meso-level public, and declarative. Because his work is not as rooted in participant observation, he has less of an opportunity to distinguish between declarative and nondeclarative culture, but that is not what he is attempting to do. However, because Young is interviewing people in two projects within a neighborhood, he is able to determine meso-level processes that could not have been discovered had he interviewed selected African American men in various American cities, or even African-American men across Chicago.

In what follows, we provide, first, an example of how ethnographic interviews are helpful through an analysis of Guhin's Fieldwork. We then more deeply engage one of the articles Lizardo cites, "Culture in Interaction" by Eliasoph and Lichterman (2003), showing how their conception of "group style" also provides a model for the importance of the ethnographic interview in engaging meso-level culture.

\section{Example 1: Author 2's Fieldwork}

Guhin's project was a comparative study of six public high schools across the United States, two each in San Diego, California, Charlotte, North Carolina, and New York, New York (see also Guhin 2018). He spent between three to five months in each city, with around 15 to 20 field visits to each site (counting days which were primarily just to collect interviews). All of these interviews were conducted at the schools themselves, and with reference to data Guhin had already gathered through classroom observations and other interviews. As such, each interview was context-rich, providing a means of checking interviewees' comments against other interviews and against his field notes and 
memos. The context-rich nature of those interviews allowed for basic fact-checking (Duneier 2011) and the development of a deeper sense of the schools' meso-level public cultures.

For example, at one of Guhin's schools, there was an emphasis on International

Baccalaureate classes. Respondents viewed these classes differently: some insisted that "IB" integrated the entire school, while others insisted it divided the schools both by class and by race. Guhin's ethnographic observation revealed that there were students of color in IB classes, but by observing those classes, he could see how many students of color in the class still sat with (and primarily spoke with) people of the same race or ethnic group. This also gave him something to ask about when interviewing IB students and teachers in one-on-one conversations, as well as when talking to teachers who were frustrated by the IB program. There were various modes of culture in conflict here: a broader public macro-level commitment to the integrating capacity of IB, a mesolevel tension between those who want to hold to this macro-level commitment and those who reject it as ultimately privileging white students, and then both personal declarative comments revealed in interviews and personal nondeclarative behavior revealed through observation.

Importantly, this focus on tensions at the meso level moves beyond debates about attitudes vs. actions: what is being analyzed is no longer simply whether people's actions match their attitudes but rather how personal declarative culture revealed in interviews interacts with (rather than contradicts or proves) other modes of culture, not only the personal nondeclarative, but also public culture at the macro and meso-levels.

Elements of meso-level public culture are revealed both in interviews that elicit declarative culture (statements about the school) and ethnographic observation that reveals nondeclarative culture (how and where students sit and how teachers and students relate to each other, some of which certain teachers did not even notice until Guhin pointed it out). These declarative, nondeclarative, and meso-level public cultural modes all simultaneously interact with broader, 
macro-level public cultural forms, in this case the commitments of the IB program and macro-level “collective representations" (Eliasoph and Lichterman 2003) about the role of public education in society to reduce racial inequality.

Other scholars have compared ethnographic fieldwork to the film Rashomon (Heider 1988), in which different witnesses to a murder all describe radically different scenes. Adjudicating the truth between separate claims can be important, but as Lizardo helps us to see, perhaps the problem is not always a better or worse interpretation but rather the need to recognize which cultural mode(s) that interpretation presupposes. Both interviews and ethnography are very good at describing some of these tensions, as we have described above. Yet ethnographic interviews are particularly good tools for examining the tension between meso-level public culture and other cultural modes.

To return to the school with the International Baccalaureate program, in his first interview at the school, Guhin interviewed the coordinator of the IB program. Without being prompted, the teacher stated "Our ethnic ratios, in the IB program, reflect the general school population. We feel pretty good about that." When Guhin responded "that's always the criticism of these sorts of things," the interviewee agreed:

It's not just affluent white kids that are in our IB program. Definitely, we have students that are in higher socio-economic groups that are part of our IB, and they represent a good number of our students, but they do not represent the majority. They represent, typically, the $20 \%-25 \%$ of kids that come from the [local] community... [those who graduate] with a full IB certificate, again, it's that reflection of the school population. Our demographic is basically, ethnic wise, is right around 64\%-65\% Hispanic, we have around $7 \%$ or $8 \%$ African American, we're right around $22 \%-25 \%$ white, Asian is probably about $4 \%$ or $5 \%$, it's small. ... people say, "Is the IB program a school within a school?" That's not true. We're a program at [the] High School, but we are not a school within a school. 
The respondent here reveals various modes of culture at once. On one level is the macro-level public culture (part of broader conversations about public education), emphasizing the importance of racial and economic equality of opportunity, both between public schools and within them. There is also the focus on declarative culture: what is here being declared about the importance of that struggle for equity and the commitment of the IB program at this school to work for it. We get a hint at the meso-level public culture in that the teacher describes what happens at the school and its commitments, but this is so far only one declaration of that culture, and it will require additional ethnographic work to piece the meso level together, potentially revealing tension at the school about the role of IB.

More research revealed that tension about IB was alive and well, as revealed from the observations described above and interviews with faculty and students. Before talking about IB, the interviewer asked a senior Vietnamese-American girl if she felt like the school was united. She responded, "I think that the school is kind of separated because, for example, freshman and sophomore year there's no IB classes, so we all have the same classes together. We're all diverse and it's not based on anything. But when you get to IB, the student who wants to work hard goes to IB and then the students who don't want to, they go to different class. For me, since I'm in IB, I know the same group of people." Similarly, when Guhin asked a teacher about IB, she told him, "IB is the more intelligent kids hanging out with each other, mostly white, and other groups that kind of join them." She added that she does not teach IB students and neither would she want to.

There was an inequality and a tension revealed within the school that marked the school's meso-level culture but also showed different forms of declarative culture with different degrees of tight coupling with nondeclarative culture. The tension around IB, Guhin realized, revealed a tension within the school between wealthy local students (many of whom were white) and the majority of students—-mostly black and Latino/a — who were bussed in from other parts of the 
school district. The fact of bussing affected elements of the school's daily experience such as who could participate in sports and whose parents could attend an evening awards ceremony. However, it was less the bussing itself than the sense that the school was a group of relatively autonomous communities that most marked daily life. Because most students ate outside, lunch time was even more segregated than it is in most schools: different racial groups ate at literally different ends of the school. A declarative cultural commitment to community (revealed in interviews, often with white faculty) ran into the nondeclarative cultural reality of segregation, both in the sense of personal nondeclarative culture of individual habituated actions that Lizardo describes (where a student sits, how a student reacts to students of other races) and the broader sense of a nondeclarative doxa shared within a social field (Bourdieu 1991).

Whether or not certain teachers overestimated how white the IB graduating class actually was, the percentage of local (wealthy, mostly white) students in IB was larger than their percentage in the school itself, exacerbating school tensions. There was even a rumor that one of the local students — a white girl — wanted a separate prom to be distinct from the kids bussed in. Guhin heard another rumor that the rumor had been started by someone going up against that girl for a student election, hoping to make her unpopular. Whether or not either rumor is true, they reveal the simmering racial and class tensions within the school. They also reveal how ethnographic interviews that pull from the same location can present a meso-level culture unavailable to broader interviewbased studies.

As Young (2006) points out, interviews are often a necessary means of getting at how respondents understand, interpret, and observe the social processes in which they are embedded. Those revealed observations (found in interviews) can be just as meaningful as the ethnographer's own. As we have already stated, the point of an ethnographic interview is not only the interview, but the sociological leverage the interview provides when added to other forms of data gathering. It's 
helpful to know what our respondents declare, and then we can compare those declarations to other declarations, as well as to what we have observed. All that knowledge has a dialectical relationship to further interviews and observations.

For example, Janet, a senior African American girl in IB told Guhin, "When I took tours here freshman year and they were touring the IB class, and touring in orientation, all of them were white. I'm like, Oh, I'm about to come to a school for the white kids.... When I got here, I was surprised that how few white kids there actually are here." Janet was the only self-identified AfricanAmerican senior in IB. As she told Guhin, “'The other girl that's in IB who's half black, half Latina, she's like, 'Yeah, I'm half black, but I'm not black. All my friends are white. I'm not really black like you are.' I was like ... It was brought up before that I was the only black girl in IB and I was like [the other girl's name] is too. She was like, 'Oh, I'm not really black.'"

That tension extended to Janet's senior year experience, something Guhin was able to ask about given previous participant observation in the school. There had been tension in the school about the prom and other graduation events as planned by the 2014 class committee. Guhin asked Janet if she was on the committee.

Janet: I kind of was, but it was like ... The people that are in the committee are my friends, so

I actually know all of them personally but ...

Jeff: A lot of them are IB, right?

Janet: Yeah, all of them are.

Jeff: They're all basically white?

Janet: Yeah, all of them are white and there's one Asian...

Jeff: Did you ever feel excluded from that group because you weren't from [the local area], or like you weren't a full part of that group? 
Janet: No. I mean I've been to their houses. I've hung out with them outside of school. I never felt excluded, but at the same time I didn't feel as comfortable. I went to their houses, and it's a totally different background. I never understood how much they didn't know about a lot of other cultures or how ignorant they were to a lot of things in black culture or any culture. I went to my friend's house, and there was a girl named Sam there. You know the Trayvon Martin shooting?

Jeff: Yeah. Yeah.

Janet: Me and my friends were talking about it, me and my black friends. We were just talking about it. Then she was like, "It's his fault. Why does everybody care because he's black" type of thing. It really showed how different everyone is in this school, how much we don't know each other. I feel like with the kids I don't hang out with that are in IB that I talk to, we know each other on a shallow level. I really don't know about their past or they don't know about mine.

Jeff: Even the other IB kids you just know on a shallow level? Janet: Yeah, I feel like if I don't hang out with them on an every day basis, I don't know much about them.

This interview accomplishes quite a bit that would not be possible with observation alone. As often happens in conversations with respondents, Guhin gained access to descriptions of events that happen outside of the field site (even if others might have different descriptions of the same events). More importantly, interviews like the one above provide access to respondents' declarative culture and their own descriptions of nondeclarative and public cultural modes at both the meso and macro level. These can then be checked against an ethnographer's observations and the ethnographer's own awareness and the respondents' statements about broader, macro-level public culture. 
Note how a girl Janet talks about refers to "everybody" caring about Trayvon Martin "because he's black," seemingly a reference to the news or popular culture, and thereby at a macro level of public culture. Whether or not everybody does care about this or the reason why such caring might or might not occur, she is making a descriptive claim about public culture (or at least Janet is saying she was). Yet Janet responds to this with a comment about meso-level culture, also referring to a totality ("everyone”) but then saying "we don't know each other" about her school. Again, it is a separate question whether or not Janet is right people do not know each other well at her school. What is important is that both girls are making claims and judgements about public culture, yet they are doing so at quite different levels. Note also that an implicit normativity undergirds both of these, and this normativity extends from the macro-level in both cases: first, that people "should" care about racial injustice and second, that students in school "should" know each other. Again, it is a separate question whether or not these normative commitments are either (a) powerful and existent or (b) themselves moral goods. What matters is that they have an effect not only on the students' declarative culture (which other interview studies are capable of showing) but also on their meso-level public culture, that is, how students and faculty interact at school.

In some ways, the tensions within the school's meso-level public culture parallel those in the macro level: there is segregation even as there is an ostensible (even if possibly unserious) commitment to eliminating segregation, something well documented in the sociology of education literature (Cobb 2017; Lewis and Diamond 2015). Yet those same public, macro-level tensions play out differently in different contexts, and analyzing how that is the case makes arguments about public culture less generalizable but also more sensitive to local mechanisms, as called for by Vaisey (2014) and others interested in predictive power, or to intriguing paradoxes, as called for by Pugh $(2013,2014)$ and those for whom the interpretation of these conflicts is the point of the work. 


\section{Example 2: Eliasoph and Lichterman}

The examples we draw from Eliasoph and Lichterman are from their separate extended ethnographic projects (Eliasoph 1998, Lichterman 1996) as revealed in their co-written article (Eliasoph and Lichterman 2003), which Lizardo cites as an example of what he calls "semiotic practice theory." The description makes sense considering the importance of language and communication in Eliasoph and Lichterman's article. As Eliasoph and Lichterman show, "speech norms" (2003: 739) are habituated practices that mark longstanding group traits (Foucault 2012, Keane 2007). As such, Lizardo lists "semiotic practice theory" as the intersection of public culture and nondeclarative culture in his chart of various intersections (2017: 95). Yet "Culture in Interaction" reveals much more than the interaction of practices and public culture. In fact, the article shows all four modes of culture we have been describing here, as well as the role of ethnographic interviews in gaining access to this data. The article's key contribution is the idea of a "group style" marked by group boundaries, group bonds, and speech norms (2003: 739). "Group style" more or less captures what we are attempting to describe with the concept of meso-level public culture, just as their concept of “collective representations” (they use Durkheim's term) captures what we would describe as macro-level public culture.

The article itself is not as clear on the role of interviews in gathering data, but in the monographs that cover much of the same material (Eliasoph 1998, Lichterman 1996) the authors describe the role of interviews in gaining access to what Lizardo would call "declarative culture". Interviews played an important role in the authors' understanding of their research sites, but they do so within an ethnographic context, providing access to group style (2003: 735). It is not only through observation that such group styles can be understood, but also through explicit talk with respondents, albeit always with reference to the ethnographic context, revealing not only implicit, unspoken practices or doxa but also a meso-level culture (a "group style") emergent within the 
group. As in her empirical contribution to "Culture in Action," Eliasoph uses bar patrons at a

Buffalo Club as a case in her 1998 book, Avoiding Politics. In that book, it is precisely the difference between how people talk about politics in large groups and how they talk about politics in interviews (or "intimate conversation") that motivates the book's investigation (1998: 7). Because Eliasoph had access to both kinds of data, one was not superior to the other but rather provided a puzzle that the ethnographic context, combined with the interview, gave the possibility of answering.

In this sense, Eliasoph and Lichterman show how talk is never cheap when talk has a context. Yet this context cannot be assumed, which, they argue, is a problem for studies of culture that build upon interview evidence, especially when interviews "assume a 'default' setting" thereby holding group style "relatively constant" (2003: 743). And here is where Lizardo's article_and our addition to it—has something to add to Eliasoph and Lichterman. We suggest that the interview projects Eliasoph and Lichterman cite (e.g. Wuthnow 1991; Hart 1992) are not sociologically lacking for their focus on what the authors refer to as "collective representations" (2003: 736), because these projects are interested in understanding broader public culture.

Eliasoph and Lichterman are surely correct when they argue that "one cannot fully understand a group's shared culture in an everyday setting without understanding the group style.” Yet the next line goes perhaps too far: "So, while agreeing with the recent emphasis on publicly communicated, collective representations, this article views the cultural concept in a more fully sociological way_-by analyzing collective representations as groups communicate them in interaction" (2003: 737). Of course, the definition of sociology is itself contested terrain, but it might be fairer to say that the concept of group style provides "a more fully ethnographic way" of studying culture, precisely in that the focus is on groups.

But this small correction of Eliasoph and Lichterman has important implications for methodological turf wars in the sociology of culture and beyond. Because if what they are suggesting 
is actually an effort to make the study of culture more ethnographic rather than more sociological, then it leaves open the possibility that other forms of learning about culture — even the randomly selected interview—can get at culture too, but simply in different modes.

\section{Discussion}

Eliasoph and Lichterman use the example of a Coltrane rendition of "My Favorite Things" to explain the relationship between group style and "collective representations" (2003: 736): just as the song has a recognizable melody but Coltrane's performance is uniquely his own, so a collective representation like American individualism is recognizable in a variety of settings but a certain group will have a particular style through which to enact it (2003: 746). This is not altogether different from what we have been describing as the relationship between macro-level public culture and the meso-level public culture ethnography reveals.

However, the analogy is not perfect, especially because Coltrane is an individual. We suggest a different analogy that allows for a defense of the study of culture at various levels. Think of the play Macbeth, something shared across a culture. People can (and do) study Macbeth entirely as a play, without any reference to how it is enacted in daily life. Or they might examine how one specific actor interprets Lady Macbeth’s “out damned spot” speech. Finally, they might examine an actual performance of the play with a setting, costumes, and various actors interacting. What we are describing here is the difference between the macro-level public, the personal, and the meso-level public. Note as well that the study of the personal refers to how the actor relates to the play in general, rather than how their performance worked in a specific production. Of course, actors from plays give speeches as parts of plays, not simply on their own!

Yet interviews are often just that: on their own. They do not capture the interactions about which we are interested. That does not mean such interviews are sociologically unimportant or 
uninteresting. By distinguishing between macro-level public culture and meso-level public culture, we are better able to understand not only the specific contributions of ethnographic interviews, which has been our primary focus here, but also the contribution of randomly selected interviews, which still engage with real sociological phenomena at both the personal and macro levels. The question then shifts from whether or not talk is cheap to which modes of culture certain kinds of talk allow us to engage.

Understanding the cultural value of talk requires us to understand not only that the talk is itself a distinct cultural mode but also that it references and relates to still other cultures modes. While Lizardo's distinction between public, declarative, and nondeclarative gets us part of the way to this understanding, the specific contribution of ethnographic interviews is only obvious when we divide public culture into its meso and macro levels. In fact, in so doing, we not only recognize why and how ethnographic interviews are helpful; we are also able to defend more standard interview studies (those with much less context) by showing how they simply engage a different interaction, that of the declarative with macro-level public culture. The important point here is not whether interviewers gain access to culture but rather which culture the method accesses. Ethnographic interviews, as we have been describing them, are helpful in that they provide access to all three modes of culture Lizardo describes. In an ethnographic interview, the difference between attitudes and behavior goes from being a problem to being data; in some contexts, it might even be the goal.

As we have said, using individual interviews to tease out macro-level public cultural narratives is a standard practice for sociology. But for scholars who are interested in meso cultures, we propose that both interviews and some form of immersion in a place is necessary. Our arguments here suggest several "tricks of the trade" that could allow ethnographic interviewers to better observe and analyze interactions between different modes of culture. Some of these are already best practices for many ethnographers, but the reasons for doing them have not been fully 
articulated or connected to theories of culture. These tips could be especially useful for those scholars embarking on a study which might have been intended as an ethnography but, due to limitations of access or time, the researcher is only able to conduct separate interviews. In these research situations, it is especially important to develop a sense of the macro level of culture through and across interviews.

1. Interviews as part of a series of interactions. As Pugh (2013) notes, interviews are social experiences with moments of interaction between ideas, emotions, and cultural frames. But they are also interactions between interviewer and respondent, and if they are done within a context of immersion, they may not be the only interaction between these two actors. Interviewers should consider why respondents present themselves in a particular way in this interaction, why they use (or do not use) particular narratives, as well as how the presence of the interviewer, and past or potential future interactions between the interviewer and the respondent might influence the interview. Indeed, as Duneier (2007) points out, one of the strengths of ethnography is the ability to follow individuals through different local groups and networks (ie, meso-level culture). If possible, the interviewer should pay close attention to other kinds of interactions with the same respondent to see how that person engages in different situations or fields.

2. Bringing immersive knowledge to bear on the interview. Interviews within an immersive context are an opportunity to talk to respondents about macro public culture, meso public culture, and personal culture. To do this well, the interviewer should have knowledge of public culture in both its macro and meso forms. Thus, we recommend that social scientists engage in fieldwork before embarking on formal interviews. Indeed, both authors (Rinaldo 2013, Guhin 2013, 2018) only began doing interviews about halfway through their ethnographic fieldwork. This is common for ethnographers, but less so for 
primary ethnographic interviewers. We think that with knowledge of both the macro and the meso context, the interviewer can be more strategic about choosing respondents as well as crafting interview questions. Indeed, if the meso culture is important to the analysis, the interview is an important opportunity to ask respondents to reflect on the meso culture and their participation in it. For example, this was crucial to Rinaldo (2013) being able to develop her analysis of how different approaches to interpreting religious texts shaped different kinds of activism and political goals in Indonesian women's organizations.

3. Interviews as opportunities to revisit or anticipate situations. If interviews are an opportunity to ask respondents to reflect on macro or meso public culture, and if the interviewer has been able to observe that culture prior to the interview, then interviews are also an excellent chance to encourage respondents to reflect on their actions or their interpretations of situations, especially those involving meso culture. This could even extend to anticipated situations. Seeing interviews as opportunities to revisit or anticipate situations provides both the interviewer and the respondent a chance to consider how and why people might change across situations or cultural modes. This is evident in Mische's (2014) recent work on projected futures. Such an interview may also give the interviewer useful data about personal culture's interactions with meso culture.

4. Interviews as Prompts for Memo Writing and Hypothesis Testing. Interviews often provide hypotheses from respondents' own talk, such as Guhin's respondent, Janet, claiming few in the school really know each other or the IB teacher claiming that the IB program was not a "school within a school." Researchers can use these kinds of comments to develop memos that will guide further research and they can test these from-the-field hypotheses through observation and other interviews. This is very similar to the approach of 
abductive analysis (Timmermans and Tavory 2012), which toggles back and forth between research and theory. The point of such "testing" should not simply be to prove whether "talk is cheap," that is, whether the claim is true or false. Instead, the point of engaging this kind of talk and checking it against and alongside further information is to determine what the talk accomplishes both for the individual in the performative moment of that interview (Pugh 2013) and more broadly within the meso-level context.

\section{Conclusion}

We have been referring to our argument's relevance in terms of the sociological study of culture, both because many of the recent conversations about interviews have occurred within cultural sociology (e.g. Vaisey 2009, Pugh 2014) and because we use Lizardo’s (2017) conceptualization of cultural modes to develop our explanation of the ethnographic interview. Mohr and Ghaziani (2014) recently observed that cultural sociologists are grappling with how to operationalize culture and break it down into observable analytic units, and our conception of meso culture is an additional step in this direction, paralleling the work of others in the recent special issue of Theory and Society, "Measuring Culture," especially McDonnell's use of "productive methods"people actually creating a cultural object together-as a means of studying "shared automatic cognition and resonance" that are not readily accessible through other means (2014).

However, beyond cultural sociology there are many subfields that might also benefit from an analysis of the ethnographic interview and the cultural modes it reveals. For instance, ethnographic studies within the sociologies of economics, labor, and politics might emphasize the disjuncture between multiple interests in different situations or fields rather than between multiple cultural structures, yet the resulting argument would be quite similar. Lee's study of Chinese labor protests (1988) is a perfect example of situating interviews alongside ethnographic fieldwork as a means of 
showing the complicated and changing nature of economic and political interests as well as showing how meso-level mechanisms can explain broader social processes.

As Burawoy (2009) argues in his defense of sociology as a reflexive science, "Reflexive science...takes context and situation as its points of departure” (30). To return to Mills's classic article on how to understand people's claims, it's the context that matters in explaining the talk: yet it's often talk that helps us to understand the context:

What is reason for one man is rationalization for another. The variable is the accepted vocabulary of motives, the ultimates of discourse, of each man's dominant group about whose opinion he cares. Determination of such groups, their location and character, would enable delimitation and methodological control of assignment of motives for specific act. (1940: 910; italics in the original).

It is the ethnographic interview's dialectical commitment to the interactions between the various cultural modes, including the meso and macro levels of public culture, that helps scholars to make such group determinations. This is also an important distinction between other sociologists' commitment to understanding how people change between situations (Lahire 2011, Trouille and Tavory 2016): while ethnography certainly has access to these changes as well, a study of the interaction between distinct modes is not quite the same thing, and future work on cultural modes can help to clarify these differences.

The ethnographic interview is not a perfect method, nor is it even necessarily a method in itself: it only becomes an ethnographic interview if it is part of an immersive project. Ethnographic interviews have the same problems with "representativeness" as many other qualitative methods; social scientists should use them for purposes of saturation rather than representativeness (Small 2009). Nonetheless, even if ethnography can mean a lot of things to a lot of people, for many 
ethnographers, a good amount of our work is just talking to people. We hope that this article has given some context on how and why that talk is worthwhile. 
By Rachel Rinaldo and Jeffrey Guhin (Forthcoming in Sociological Methods and Research)

\section{Endnotes}

1 Authors are listed in reverse alphabetical order. Both authors contributed equally to this article. 


\section{References}

Abbott, Andrew. 2001. Chaos of Disciplines. Chicago: University of Chicago Press.

Alexander, Jeffrey C. 2006. The Meanings of Social Life: A Cultural Sociology. New York: Oxford University Press.

Alexander, Jeffrey C and Philip Smith. 2010. "The Strong Program: Origins, Achievements, and Prospects." Handbook of cultural sociology:13-24.

Bauman, Laurie J and Elissa Greenberg Adair. 1992. "The Use of Ethnographic Interviewing to Inform Questionnaire Construction." Health Education Quarterly 19(1):9-23.

Bellah, Robert N, Richard Madsen, William M Sullivan, Ann Swidler and Steven M Tipton. 2007. Habits of the Heart: Individualism and Commitment in American Life. Berkeley: Univ of California Press.

Biernacki, Richard. 1995. The Fabrication of Labor: Germany and Britain, 1640-1914. Berkeley: Univ of California Press.

Blumer, Herbert. 1986. Symbolic Interactionism: Perspective and Method. Berkeley: University of California Press.

Bourdieu, Pierre. 1990. The Logic of Practice. Translated by R. Nice. Stanford, CA: Stanford University Press.

Bourdieu, Pierre. 1991. Language and Symbolic Power. Translated by G. Raymond and M. Adamson: Harvard University Press.

Burawoy, Michael. 2009. The Extended Case Method. Berkeley: University of California Press.

Burke, Kelsy. 2016. Christians Under Covers: Evangelicals and Sexual Pleasure on the Internet. Berkeley: University of California Press.

Cerulo, Karen A. 2014. "Reassessing the Problem: Response to Jerolmack and Khan." Sociological Methods \& Research 43(2):219-26.

Charmaz, Kathy. 2006. Constructing Grounded Theory: A Practical Guide through Qualitative Research. London: Sage Publications.

Cicourel, Aaron V. 1982. "Interviews, Surveys, and the Problem of Ecological Validity." The American Sociologist 17(1):11-20.

Cobb, Jessica S. 2017.” Inequality Frames: How Teachers Inhabit Color-blind Ideology.” Sociology of Education 90(4): 315-332.

Decoteau, Claire Laurier. 2016. "The Reflexive Habitus: Critical Realist and Bourdieusian Social Action." European Journal of Social Theory 19(3):303-21.

Desmond, Matthew. 2012. "Disposable Ties and the Urban Poor." American Journal of Sociology 117(5):1295-335.

Desmond, Matthew. 2014. "Relational Ethnography." Theory and society 43(5):547-79.

Desmond, Matthew. 2016. Evicted: Poverty and Profit in the American City. New York: Broadway Books.

Duneier, Mitchell. 2007. "On the Legacy of Elliot Liebow and Carol Stack: Context-Driven

Fieldwork and the Need for Continuous Ethnography." Focus 25(1):33-38.

Duneier, Mitchell. 2011. "How Not to Lie with Ethnography." Sociological Methodology 41(1):1-11.

Durkheim, Emile. 1995. The Elementary Forms of Religious Life. Translated by K. E. Fields. New York: The Free Press.

Edin, Kathryn and Maria Kefalas. 2011. Promises I Can Keep: Why Poor Women Put Motherhood before Marriage. Berkeley: University of California Press.

Eliasoph, Nina. 1998. Avoiding Politics: How Americans Produce Apathy in Everyday Life. New York: Cambridge University Press. 
Eliasoph, Nina and Paul Lichterman. 2003. "Culture in Interaction." American Journal of Sociology 108(4):735-94.

Emerson, Robert M, Rachel I Fretz and Linda L Shaw. 2011. Writing Ethnographic Fieldnotes. Chicago: University of Chicago Press.

Fine, Gary Alan. 2003. "Towards a Peopled Ethnography: Developing Theory from Group Life." Ethnography 4(1):41-60.

Foucault, Michel. 2012. The History of Sexuality: Volume 1. Translated by R. Hurley. New York: Vintage Books.

Geertz, Clifford. 2008. Local Knowledge: Further Essays in Interpretive Anthropology. New York: Basic Books.

Gerson, Kathleen. 2009. The Unfinished Revolution: Coming of Age in a New Era of Gender, Work, and Family. New York: Oxford University Press.

Gibson, D.R. 2008. "Doing Time in Space: Line-Joining Rules and Resultant Morphologies." Sociological Forum 23(2): 207-233.

Goffman, Erving. 1956. The Presentation of Self in Everyday Life. Random House.

Goodman, Philip. 2008. "“It's Just Black, White, or Hispanic": An Observational Study of Racializing Moves in California's Segregated Prison Reception Centers." Law \& Society Review 42(4):735-70.

Guhin, Jeffrey. 2018. “Urban Public High Schools: Self-Actualization vs. Citizenship?” Pp. 2141 in The Content of their Character: Inquiries into the Varieties of Moral Formation. Finstock \& Tew Publishers.

Guhin, Jeffrey. 2013. The Work of Knowing: Science, Religion, and Tradition in Evangelical and Sunnin Schools. Dissertation. Yale University.

Haidt, Jonathan. 2001. "The Emotional Dog and Its Rational Tail: A Social Intuitionist Approach to Moral Judgment." Psychological Review 108(4):814-34.

Hart, Stephen. 1992. What does the Lord Require? How American Christians Think about Economic Justice. New Brunswick: Rutgers University Press.

Heider, Karl G. 1988. "The Rashomon Effect: When Ethnographers Disagree." American Anthropologist 90(1):73-81.

Husain, Atiya. 2017. "Moving Beyond (and Back to) the Black-White Binary: A Study of Black and White Muslims' Racial Positioning in the United States." Ethnic and Racial Studies:1-18.

Jerolmack, Colin and Shamus Khan. 2014. "Talk Is Cheap: Ethnography and the Attitudinal Fallacy." Sociological Methods \& Research 43(2):178-209.

Kahneman, Daniel. 2011. Thinking, Fast and Slow. New York: Farrar, Straus and Giroux.

Katz, Jack. 1996. "Families and Funny Mirrors: A Study of the Social Construction and Personal Embodiment of Humor." American Journal of Sociology 101(5):1194-237.

Keane, Webb. 2007. Christian Moderns: Freedom and Fetish in the Mission Encounter. Berkeley: University of California Press.

Kitsuse, John I. 1962. "Societal Reaction to Deviant Behavior: Problems of Theory and Method." Social Problems 9(3):247-56.

Kligman, Gail and Katherine Verdery. 2011. Peasants under Siege: The Collectivization of Romanian Agriculture, 1949-1962. Princeton: Princeton University Press.

Lahire, Bernard. 2011. The Plural Actor. Translated by D. Fernbach. Malden, MA: Polity.

Lamont, Michèle. 1992. Money, Morals, and Manners: The Culture of the French and the American UpperMiddle Class. Chicago: University of Chicago Press.

Lamont, Michèle. 2009. The Dignity of Working Men: Morality and the Boundaries of Race, Class, and Immigration. Cambridge, MA: Harvard University Press. 
Lamont, Michèle and Ann Swidler. 2014. "Methodological Pluralism and the Possibilities and Limits of Interviewing." Qualitative Sociology 37(2):153-71.

Lee, Ching Kwan. 1998. Gender and the South China Miracle: Two Worlds of Factory Women. Berkeley: University of California Press.

Lewis, Amanda E and John B Diamond. 2015. Despite the Best Intentions: How Racial Inequality Thrives in Good Schools. New York: Oxford University Press.

Lichterman, Paul. 1996. The Search for Political Community: American Activists Reinventing Commitment. New York: Cambridge University Press.

Liebow, Elliot. 2003. Tally's Corner: A Study of Negro Streetcorner Men. Lanham, MD: Rowman \& Littlefield.

Lizardo, Omar and Michael Strand. 2010. "Skills, Toolkits, Contexts and Institutions: Clarifying the Relationship between Different Approaches to Cognition in Cultural Sociology." Poetics 38(2):205-28.

Lizardo, Omar. 2017. "Improving Cultural Analysis: Considering Personal Culture in Its Declarative and Nondeclarative Modes." American Sociological Review 82(1):88-115.

Luker, Kristin. 2007. When Sex Goes to School: Warring Views on Sex--and Sex Education-since the Sixties. New York: WW Norton \& Company.

Marcus, George. 1995. "Ethnography in/of the World System: The Emergence of Multi-Sited Ethnography." Annual Review of Anthropology 24(95-117).

Maynard, Douglas W and Nora Cate Schaeffer. 2000. "Toward a Sociology of Social Scientific Knowledge: Survey Research and Ethnomethodology's Asymmetric Alternates." Social studies of science 30(3):323-70.

McDonnell, Terence E. 2014. "Drawing out Culture: Productive Methods to Measure Cognition and Resonance." Theory and society 43(3-4):247-74.

Mead, George Herbert. 1967. Mind, Self, and Society. Chicago: University of Chicago Press.

Mears, Ashley. 2014. "Seeing Culture through the Eye of the Beholder: Four Methods in Pursuit of Taste." Theory and society 43(3-4):291-309.

Merton, Robert K, Marjorie Fiske and Patricia L. Kendall. 1990. The Focused Interview: A Manual of Problems and Procedures. New York: The Free Press.

Mills, C Wright. 1940. "Situated Actions and Vocabularies of Motive." American Sociological Review 5(6):904-13.

Mische, Ann. 2014. "Measuring Futures in Action: Projective Grammars in the Rio +20 Debates." Theory and society 43(3-4): 437-464.

Mohr, John W and Amin Ghaziani. 2014. "Problems and Prospects of Measurement in the Study of Culture." Theory and society 43(3-4):225-46.

Pugh, Allison J. 2013. "What Good Are Interviews for Thinking About Culture? Demystifying Interpretive Analysis." American Journal of Cultural Sociology 1(1):42-68.

Pugh, Allison J. 2014. "The Divining Rod of Talk: Emotions, Contradictions and the Limits of Research." American Journal of Cultural Sociology 2(1):159-63.

Riesman, David and Mark Benney. 1956. "The Sociology of the Interview." The Midwest Sociologist 18(1):3-15.

Rinaldo, Rachel. 2013. Mobiliæing piety: Islam and feminism in Indonesia. Oxford University Press.

Ryle, Gilbert. 1945-1946. "Knowing How and Knowing That: The Presidential Address." Proceedings of the Aristotelian Society, new Series 46:1-16.

Ryle, Gilbert. 2009. The Concept of Mind. New York: Routledge.

Sewell, William H. 1992. "A Theory of Structure: Duality, Agency, and Transformation." American Journal of Sociology 98(1):1-29. 
Small, Mario Luis. 2009. "How Many Cases Do I Need?: On Science and the Logic of Case Selection in Field-Based Research." Ethnography 10(1):5-38.

Spradley, James. 1979. The Ethnographic Interview. Belmont, CA: Wadsworth.

Swidler, Ann. 1986. "Culture in Action: Symbols and Strategies." American Sociological Review 51(2):273-86.

Swidler, Ann. 2001. Talk of Love: How Culture Matters. Chicago: University of Chicago Press.

Timmermans, Stefan and Iddo Tavory. 2012. "Theory Construction in Qualitative Research: From Grounded Theory to Abductive Analysis." Sociological Theory 30(3): 167-186.

Tavory, Iddo. 2016. "Summoned: Identification and Religious Life in a Jewish Neighborhood." Chicago: University of Chicago Press.

Tavory, Iddo. 2018. "Between Situations: Anticipation, Rhythms, and the Theory of Interaction." Sociological Theory 36(2):117-33.

Trouille, David and Iddo Tavory. 2016. "Shadowing: Warrants for Intersituational Variation in Ethnography." Sociological Methods \& Research.

Vaisey, Stephen. 2009. "Motivation and Justification: A Dual-Process Model of Culture in Action." American Journal of Sociology 114(6):1675-715.

Vaisey, Stephen. 2014. "Is Interviewing Compatible with the Dual-Process Model of Culture." American Journal of Cultural Sociology 2(1):150-58.

Vaughan, Diane. 1997. The Challenger Launch Decision: Risky Technology, Culture, and Deviance at Nasa. Chicago: University of Chicago Press.

Vaughan, Diane. 2004. "Theorizing Disaster: Analogy, Historical Ethnography, and the Challenger Accident." Ethnography 5(3):315-47.

Viterna, Jocelyn and Douglas W Maynard. 2002. "How Uniform Is Standardization? Variation within and across Survey Research Centers Regarding Protocols for Interviewing." in Standardization and Tacit Knowledge: Interaction and Practice in the Survey Interview, edited by D. W. Maynard, H. Houtkoop-Steenstra, N. C. Schaeffer and J. v. d. Zouwen. New York: John Wiley \& Sons.

Warren, Carol AB. 2012. "Interviewing as Social Interaction." Pp. 129-42 in Sage Handbook of Interview Research: The Complexity of the Craft, edited by J. F. Gubrium, J. A. Holstein, A. B. Marvasti and K. D. McKinney. Thousand Oaks: SAGE Publications.

Weiss, Robert S. 1995. Learning from Strangers: The Art and Method of Qualitative Interview Studies. New York: Simon and Schuster.

Wittgenstein, Ludwig. 2009. Philosophical Investigations. Translated by G. E. M. Anscombe, P. M. S. Hacker and J. Schulte. Malden, MA: Blackwell Publishing.

Wuthnow, Robert J. 2011. "Taking Talk Seriously: Religious Discourse as Social Practice." Journal for the Scientific Study of Religion 50(1):1-21.

Young, Alford A. 2006. The Minds of Marginalized Black Men: Making Sense of Mobility, Opportunity, and Future Life Chances. Princeton: Princeton University Press. 